\title{
Detection and Characterization of Novel Rotavirus Strains in the United States
}

\author{
M. RAMACHANDRAN,${ }^{1}$ J. R. GENTSCH, ${ }^{1 *}$ U. D. PARASHAR, ${ }^{1,2}$ S. JIN,${ }^{1}$ P. A. WOODS,${ }^{1}$ J. L. HOLMES, ${ }^{1}$ \\ C. D. KIRKWOOD ${ }^{1}$ R. F. BISHOP,${ }^{3}$ H. B. GREENBERG,${ }^{4}$ S. URASAWA,${ }^{5}$ G. GERNA, ${ }^{6}$ B. S. COULSON, ${ }^{7}$ \\ K. TANIGUCHI ${ }^{8}$ J. S. BRESEE ${ }^{1}$ R. I. GLASS, ${ }^{1}$ AND THE NATIONAL ROTAVIRUS \\ STRAIN SURVEILLANCE SYSTEM COLLABORATING LABORATORIES $\dagger$ \\ Division of Viral and Rickettsial Diseases, National Center for Infectious Diseases, ${ }^{1}$ and Epidemic Intelligence Service, Epidemiology \\ Program Office, ${ }^{2}$ Centers for Disease Control and Prevention, Atlanta, Georgia; Department of Gastroenterology, Royal \\ Children's Hospital, Melbourne, ${ }^{3}$ and Department of Microbiology and Immunology, The University of Melbourne, \\ Parkville, Victoria, ${ }^{7}$ Australia; Division of Gastroenterology, Stanford University School of Medicine, Stanford, \\ and The Palo Alto Veterans Administration Hospital, Palo Alto, California ${ }^{4}$; Virus Laboratory, \\ Department of Hygiene, Sapporo Medical University, Sapporo, ${ }^{5}$ and Department of Virology \\ and Parasitology, Fujita Health University, School of Medicine, Aichi, ${ }^{8}$ Japan; \\ and Viral Diagnostic Service, IRCCS Policlinico San Mateo, Pavia, Italy ${ }^{6}$
}

Received 23 April 1998/Returned for modification 8 July 1998/Accepted 11 August 1998

\begin{abstract}
We recently established a rotavirus strain surveillance system in the United States to monitor the prevalent $G$ serotypes before and after the anticipated implementation of a vaccination program against rotavirus and to identify the emergence of uncommon strains. In this study, we examined 348 rotavirus strains obtained in 1996 to 1997 from children with diarrhea in 10 U.S. cities. Strains were characterized for P and G types, subgroups, and electropherotypes by using a combination of monoclonal antibody immunoassay, reverse transcription-PCR, and hybridization. The four strains most commonly found worldwide comprised $83 \%$ of the isolates $(\mathrm{P}[8] \mathrm{G1}, 66.4 \% ; \mathrm{P}[4] \mathrm{G} 2,8.3 \% ; \mathrm{P}[8] \mathrm{G3}, 6.9 \% ; \mathrm{P}[8] \mathrm{G} 4,1.4 \%)$, but $9.2 \%$ were unusual strains (P[6]G9, 5.5\%; $P[8] G 9,1.7 \%$; P[6]G1, 1.4\%; and P[4]G1 and P[8]G2, $0.3 \%$ each). Strains not typeable for $P$ or $G$ type accounted for $5.5 \%$ of the total, while $2.3 \%$ of the strains had more than one G type (mixed infections). All P[6] G9 strains tested had short electropherotypes and subgroup I specificity and were detected in 4 of 10 cities, while P[8]G9 strains had long electropherotypes and subgroup II VP6 antigens. Both sequence analysis of the VP7 open reading frame (about 94 to 95\% amino acid identity with the VP7 gene of G9 prototype strain WI61) and binding to a G9-specific monoclonal antibody strongly suggest that U.S. G9 strains belong to serotype G9. The high detection rates of unusual rotaviruses with $\mathrm{G9}(\mathbf{7 . 2 \%})$ or $\mathrm{P}[6](6.9 \%)$ specificity in multiple U.S. cities suggest the emergence of new strains or inadequate diagnosis in the past. The epidemiologic importance of these strains remains to be determined.
\end{abstract}

Human rotavirus (HRV) is the most-common viral agent of severe childhood diarrhea in the United States, causing about 50,000 hospitalizations and 20 to 40 deaths per year at an estimated annual cost of more than $\$ 1$ billion $(25,36)$. A vaccine against HRV was recently licensed by the Food and Drug Administration and may be introduced in the United States by the end of 1998 . The vaccine, designated the rhesus rotavirus tetravalent vaccine (RRV-TV), has been formulated to protect against the four serotypes, G1 to G4 (24), that predominate in the United States as well as globally (14).

Recent studies have documented that other serotypes are

* Corresponding author. Mailing address: Viral Gastroenteritis Section MS G04, Centers for Disease Control and Prevention, 1600 Clifton Rd., N.E., Atlanta, GA 30333. Phone: (404) 639-3577. Fax: (404)639-3645. E-mail: jrg4@cdc.gov.

† The National Rotavirus Strain Surveillance System participants are Rebecca Nelson, Arkansas Children's Hospital, Little Rock, Ark.; Michelle Hartin, Children's Hospital, San Diego, Calif.; Christine C. Robinson, Children's Hospital of Denver, Denver, Colo.; Yolanda Arcilla, Medical Center of Delaware, Newark, Del.; Theresa J. Mason, Clarian Health Partners, Indianapolis, Ind.; Marilyn Hamilton, Children's Mercy Hospital, Kansas City, Mo.; Paul A. Yam, Children's Hospital, Omaha, Nebr.; DeLores Aiazzi, Washoe Medical Center, Reno, Nev.; H. Fred Clark, Children's Hospital of Philadelphia, Philadelphia, Pa.; and Tammi Johnson, Driscoll Children's Hospital, Corpus Christi, Tex. common in some regions of the world, including G9 in India and G5 in Brazil, but there has been no evidence that such strains are prevalent in the United States $(29,38)$. Serotyping surveys of HRV strains in the United States usually have resulted in 10 to $30 \%$ of strains remaining untypeable after analysis with monoclonal antibodies (MAbs) to G serotypes 1 to 4 . These findings suggest that some of these untyped strains may belong to uncommon serotypes, although sequencing and full-characterization studies demonstrate that many of these strains belong to the four common G serotypes (20). Nonetheless, because of the theoretical possibility of uncommon serotypes and the lack of data on the efficacy of RRV-TV against strains such as G5 and G9, initiation of strain surveillance systems in countries prior to and following vaccine introduction is crucial. Such studies will allow health officials to monitor the impact of vaccination programs on serotype prevalence and the emergence of uncommon strains and to provide information on the ability of vaccination to protect against diarrhea caused by serotypes other than G1 to G4.

Rotaviruses are nonenveloped, icosahedral viruses of the family Reoviridae with 11 segments of double-stranded RNA (dsRNA), each encoding at least one structural or nonstructural protein (10). Serotypes of HRV are specified by two different neutralizing antigens, VP4 and VP7, located in the outer capsid of the virion and encoded by separate genome segments. Each serotype has been shown to elicit serotype- 
specific protective immunity, and this feature has, in part, been used as the rationale for the development of vaccines incorporating the serotype antigens of the most-important human strains $(24,35)$. The two serotype specificities have been designated G, since VP7 is a glycoprotein, and P, because HRV infectivity is activated by protease cleavage of VP4 (10). RRVTV contains only $G$ serotype antigens related to the major HRV strains G1 to G4; vaccines containing the major P serotype antigen are still under development (5).

Fourteen rotavirus $\mathrm{G}$ serotypes, including 10 in humans, and $10 \mathrm{P}$ serotypes, with 8 in humans, have been identified to date by cross-neutralization studies $(10,41,44)$. Numerous serotyping surveys based on enzyme immunoassays (EIAs) with $G$ type-specific MAbs to characterize HRV strains obtained directly from fecal specimens of children with diarrhea have demonstrated that serotypes G1 to G4 are the most important globally, with type G1 being the most prevalent (14, 15, 32, 49, 50). Direct $P$ serotyping assays with MAbs have not been used routinely to type HRV in fecal specimens (31), and neutralization with culture-adapted strains is too tedious for epidemiologic studies; therefore, large-scale surveys of common $\mathrm{P}$ types have relied on the development of nucleic-acid-based typing methods, such as multiplex reverse transcription (RT)PCR and probe hybridization $(13,28)$.

P-genotyping studies have been used to demonstrate that $G$ types 1,3 , and 4 are usually found only in combination with genotype $\mathrm{P}[8]$, while serotype $\mathrm{G} 2$ is commonly found only with genotype P[4] (14). Genotyping studies conducted in developing countries have shown that the genetic diversity of rotavirus $\mathrm{P}$ and $\mathrm{G}$ types is much greater than previously believed. Thus, studies have found that strains of genotype $\mathrm{P}[6]$ previously thought to be restricted to neonates may be common in children with diarrhea in some countries (38), while G types 5 and 9 have been found to be common among children with diarrhea in India and Brazil, respectively $(29,38,45)$.

In the current study, we report the development of a strain surveillance system for the United States as well as the results of strain-typing studies for the 1996 to 1997 rotavirus season. We also report the testing of riboprobes for the most-common $\mathrm{P}$ genotypes and their use in the typing of rotavirus dsRNA directly from fecal specimens.

\section{MATERIALS AND METHODS}

Rotavirus specimens. In this pilot surveillance study, the 10 hospital-based laboratories that provided specimens were recruited primarily from among the 79 laboratories participating in the National Respiratory and Enteric Virus Surveillance System, based on their known relatively high volume of HRV testing and geographic representativeness (46). The number of participating laboratories was restricted to 10 to evaluate the feasibility of typing 250 to 350 strains per year. Each laboratory saved as many as the first 12 rotavirus-positive fecal specimens from hospital inpatients or outpatients with gastroenteritis each month during the 1996 to 1997 rotavirus season (1 November 1996 to 31 May 1997) and shipped them to the Centers for Disease Control and Prevention (CDC) near the middle of and at the end of the season. Specimens were stored and shipped frozen at $-80^{\circ} \mathrm{C}$ and were not thawed until they were used for the preparation of fecal suspensions.

Requested patient data included hospital identification number, age, date of admission, date of specimen collection, and patient type (inpatient or outpatient). Data on disease severity, patients' gender, and patients' residence and recent travel or contact with other individuals who had recently traveled were not requested for this pilot study.

Virus strains and cultivation. The origin of strains WA, DS-1, M37, and WI61 and the methods for cultivation in MA104 cells in the presence of trypsin have been described previously (8).

Plaque purification of cultivated strains. After three passages in MA104 cells, antigen-positive cultures were frozen and thawed three times, trypsinized, and frozen at $-80^{\circ} \mathrm{C}$. Three rounds of plaque purification were carried out for strain US1205 as described previously (42). A virus seed stock of US1205 and other strains was then prepared by additional passages in MA104 cells.

P genotype-specific riboprobes. Digoxigenin (DIG)-labeled riboprobes specific for the rotavirus VP4 and VP7 gene hypervariable regions $(12,28)$ were synthe- sized by in vitro transcription with DNA templates containing T7 RNA polymerase promoter sites incorporated during RT-PCR. The primer pairs used for preparation of PCR products were specific for portions of the VP4 genes of strains Wa, RV-5, and M37 and the VP7 gene of WI61 and contained a T7 polymerase site in one of the primers and restriction endonuclease sites plus three additional nucleotides in both primers of each pair (Table 1). All primers used in this study were synthesized in the Biotechnology Core Facility of the CDC. RT-PCR products were generated from dsRNA templates as described previously (13). PCR products were concentrated and used as templates for transcription with the Mega ShortScript kit (Ambion, Inc., Austin, Tex.) according to the manufacturer's instructions. The concentrations of ATP, GTP, and CTP were each $7.5 \mathrm{mM}$, while UTP and DIG-UTP (Boehringer Mannheim, Indianapolis, Ind.) were used at 6 and $1.5 \mathrm{mM}$, respectively. A control reaction mixture containing a set of five dsDNA templates ([100, 200, 300, 400, and 500 bp] Century TM Template; Ambion, Inc.) was also carried out at the same DIGUTP concentration, and the transcripts from this reaction were used to monitor the size and intactness of the rotavirus VP4 and VP7 gene transcripts by ureaacrylamide gel electrophoresis and ethidium bromide staining as suggested by the manufacturer. The amount (in micrograms) of DIG-labeled probe synthesized was estimated with the Boehringer Mannheim Genius 1 kit according to the protocol provided.

RNA extraction. Rotavirus RNA was extracted from $10 \%$ fecal suspensions by using the glass powder method, as previously described, and resuspended in diethyl pyrocarbonate-treated $\mathrm{H}_{2} \mathrm{O}$ (13). To prepare RNA for riboprobe sensitivity determinations, the standard strains Wa, DS-1, M37, and WI61 were concentrated by pelleting through sucrose cushions as previously described (13), and the dsRNA was extracted by the phenol-chloroform method followed by ethanol precipitation. After drying, the pellets were resuspended and extracted by a standard glass powder method, and the RNA concentration was determined spectrophotometrically.

RT-PCR genotyping. $P$ and $G$ genotypes were determined by heminested RT-PCR, agarose gel electrophoresis, and ethidium bromide staining $(7,13,18)$. The $\mathrm{P}$ genotypes were classified according to the suggestions of the Rotavirus Nomenclature Working Group (10).

Northern slot blot hybridization. Dilutions of dsRNA (500 to $0.8 \mathrm{ng}$ ) extracted from partially purified virions or from fecal specimens (one-third to one-half the dsRNA extracted from $500 \mu \mathrm{l}$ of a $10 \%$ stool extract) in $20 \mu \mathrm{l}$ of diethyl pyrocarbonate-treated $\mathrm{H}_{2} \mathrm{O}$ were heat denatured for $4 \mathrm{~min}$ at $97^{\circ} \mathrm{C}$, chilled for 1 min on ice, and filtered onto a nylon membrane with a 48 -well slot blot apparatus (Bio-Rad; Hercules, Calif.), and the RNAs were cross-linked to the membrane twice by using the automatic cycle of a Stratalinker (Stratagene, Inc., La Jolla, Calif.). The membrane was then prehybridized for $2 \mathrm{~h}$ in $25 \mathrm{ml}$ of prehybridization solution $(6 \times \mathrm{SSC}[1 \times \mathrm{SSC}$ is $0.15 \mathrm{M} \mathrm{NaCl}$ plus $0.015 \mathrm{M}$ sodium citrate], $50 \%$ formamide, $0.1 \%$ sodium dodecyl sulfate [SDS], $2 \%$ blocking solution) (Boehringer Mannheim) at 56 or $68^{\circ} \mathrm{C}$, depending on the probe, and then hybridized overnight at the same temperature in fresh hybridization solution containing about $1 \mu \mathrm{g}$ of DIG-labeled probe. Hybridization was carried out in screw-cap glass tubes with a scientific model 400 hybridization oven (Robbins, Sunnyvale, Calif.). Samples were washed twice at room temperature for $15 \mathrm{~min}$ with $2 \times$ SSC $-0.1 \%$ SDS and twice again at the same temperature used for hybridization with $0.5 \times$ SSC $-0.1 \%$ SDS for $15 \mathrm{~min}$, and then the bound probe was detected with anti-DIG alkaline phosphatase conjugate and CSPD substrate (Boehringer Mannheim) as described previously for detection of DIG-labeled oligonucleotide probes (1).

Sequence analysis. VP7 gene RT-PCR products for sequencing were synthesized with one primer pair that was a degenerate mixture of Beg9 (homologous to G1, G2, G3, and G4 VP7 nucleotides 1 to 28)/end9 (homologous to G1, G2, G3, G4, and G8 VP7 gene nucleotides 1036 to 1062) $(2,18,22,30,39,40)$ and primer pairs $71 / 72$ and G9C1/72 (Table 1) based on the sequence of serotype G9 strain 116E (8). PCR products were purified on Centrisep columns (Princeton Separations, Adelphia, N.J.) and sequenced with the individual primers or degenerate mixture of Beg9 or end9 described above by the dideoxynucleotide chain termination method with the BigDye sequencing kit (Applied Biosystems, Inc., Foster City, Calif.) under the thermal cycling conditions recommended by the manufacturer and a model 377 automated DNA sequencer (Applied Biosystems, Inc.). Based on the sequence obtained, additional primers were synthesized to completely sequence the VP7 open reading frames in both directions (Table 1).

Overlaps in sequence between the different products were analyzed with the Sequencher program (Gene Codes Corporation, Inc., Ann Arbor, Mich.). Comparison to other rotavirus sequences was performed with the University of Wisconsin Genetics Computer Group and Phylip 3.5 computer programs $(9,11)$.

Polyacrylamide gel electrophoresis. Extracted RNAs were resolved on $10 \%$ discontinuous gels (27) and stained with silver nitrate (37).

Antigen EIA. The Rotaclone rotavirus detection kit (Meridian Diagnostics, Inc., Cincinnati, Ohio) was used together with the protocol provided by the manufacturer. All specimens sent by the 10 laboratories were retested for rotavirus, and only those positive with the Rotaclone kit were included in this study.

G serotyping and subgrouping with MAbs. The following MAbs were used: serotype G1 (5E8, RV4-1, and KU4); G2 (IC10 and S2-2G10); G3 (Y0-1E2 and G3-159); G4 (ST-2G7, VP7 specific, and 60-F2D2); subgroup I specific (255-60); subgroup II specific (631-9); and subgroup common (631-24) (21) to G serotype 
TABLE 1. Primer pairs used for riboprobe synthesis and sequencing of U.S. G9 strains

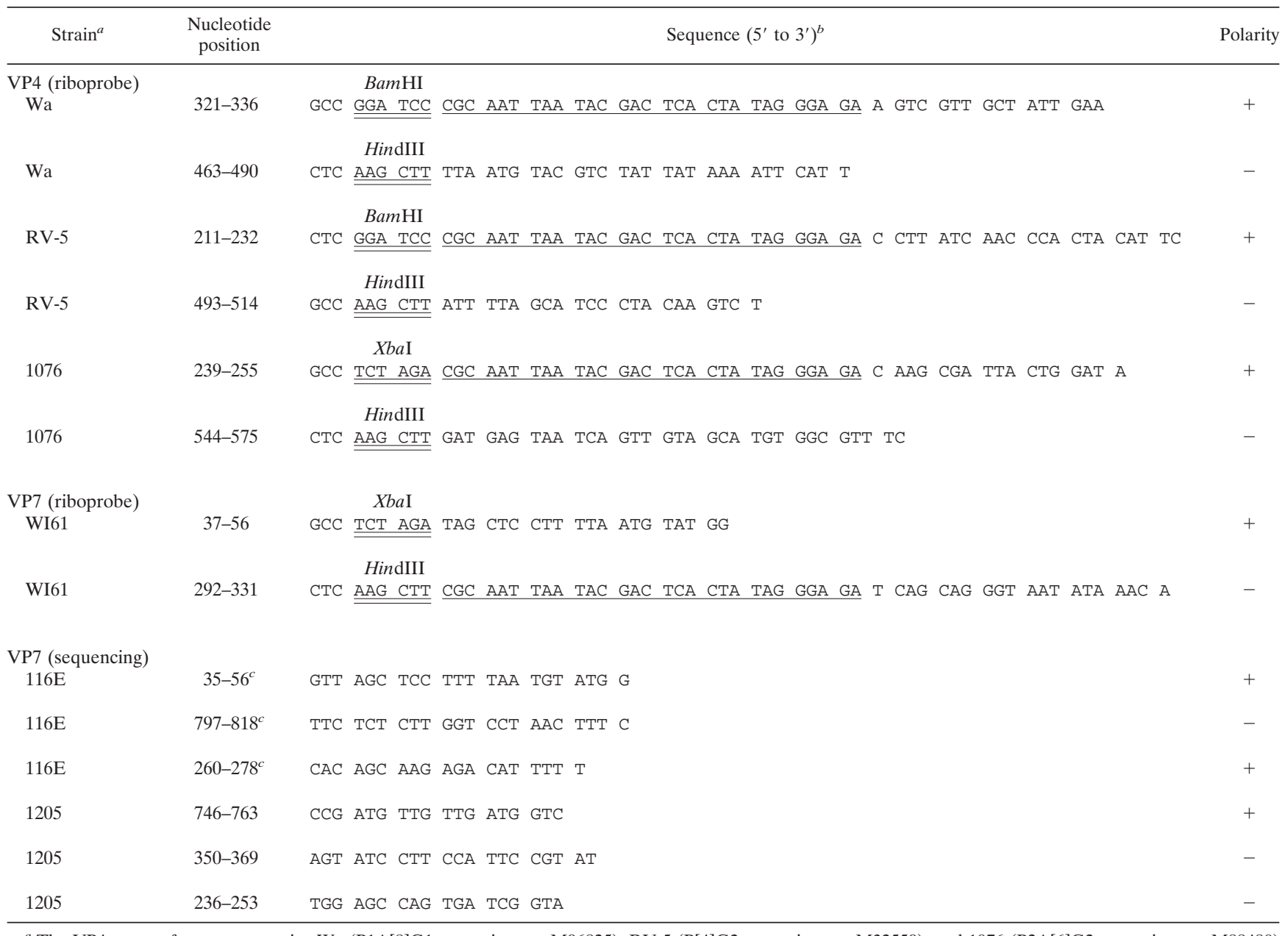

${ }^{a}$ The VP4 genes of prototype strains Wa (P1A[8]G1; accession no. M96825), RV-5 (P[4]G2; accession no. M32559), and 1076 (P2A[6]G2; accession no. M88480) were used for VP4 primer design, and WI61 (serotype G9) was used for VP7 $(17,19,23)$.

${ }^{b}$ The $5^{\prime}$-terminal three nucleotides represented were included to enhance efficiency of cleavage by restriction enzymes; restriction sites are double underlined. The T7 RNA polymerase promoter is single underlined. The rotavirus-specific sequence is in boldface type.

${ }^{c}$ This sequence was also used to generate RT-PCR products used for sequencing (primer pairs 35 to 56/797 to 818 and 260 to 278/797 to 818).

and subgroup rotaviruses in $10 \%$ fecal extracts by standard protocols $(6,21,26$, 43).

Nucleotide sequence accession number. The VP7 gene sequence described in this study (strain US1205) has been deposited in the GenBank sequence database and given accession no. AF060487.

\section{RESULTS}

P genotyping by hybridization with riboprobes. The specificity and sensitivity of $\mathrm{P}$ genotype-specific riboprobes were tested at a range of concentrations with dsRNA extracted from standard strains, while binding to rotavirus RNAs from fecal specimens was tested with one-third to one-half of the total RNA from a standard RNA extract (Fig. 1). Routine sensitivity of standard homologous RNA was approximately $20 \mathrm{ng}$, although in some experiments, sensitivity of $0.8 \mathrm{ng}$ was observed without significant cross-hybridization to heterologous dsRNAs. Low-level cross-hybridization was sometimes observed at the highest concentration of heterologous RNAs (e.g., $500 \mathrm{ng}$ of M37 RNA cross-hybridized faintly with the Wa probe). Consequently, heterologous dsRNAs of both prototype strains as well as fecal RNAs that were positive by polyacrylamide gel electrophoresis and silver staining and whose $\mathrm{P}$ genotypes had been determined by RT-PCR were included in all experiments as negative controls. Strains were assigned a $\mathrm{P}$ genotype only if the 100- and 20-ng cell culture RNA controls and fecal RNA controls showed no detectable cross-hybridization. In total, $86 \%(n=299)$ of 348 fecal specimens could be P genotyped with these probes. Of the remaining $14 \%(n=49)$ that could not be typed with riboprobes, $8.5 \%(n=30)$ were typeable by RT-PCR methods (13).

$G$ and $P$ typing of rotavirus strains. Rotavirus from fecal specimens of 348 children with diarrhea in 10 cities was $G$ typed by a combination of RT-PCR and monoclonal EIA and $\mathrm{P}$ genotyped with DIG-labeled riboprobes and RT-PCR (Table 2). Strain P[8]G1 was the most frequently detected overall (231 of 348, 66.4\%) and the most widely distributed (detected at all 10 surveillance sites); next most common were $\mathrm{P}[4] \mathrm{G} 2$ (29 of 348, 8.3\% [detected at six sites]) and P[8]G3 (24 of 348, $6.9 \%$ [detected at seven sites]) (Table 2). Unexpectedly, the fourth-most-common strain was genotype P[6]G9 (19 of 348, $5.5 \%$ ), followed by two other strains thought to be rare in developed countries, P[8]G9 (6 of 348, 1.7\%) and P[6]G1 (5 of $348,1.4 \%$ ). Together, the two strain types bearing genotype G9 were found in four cities and represented $7.2 \%$ of the strains 

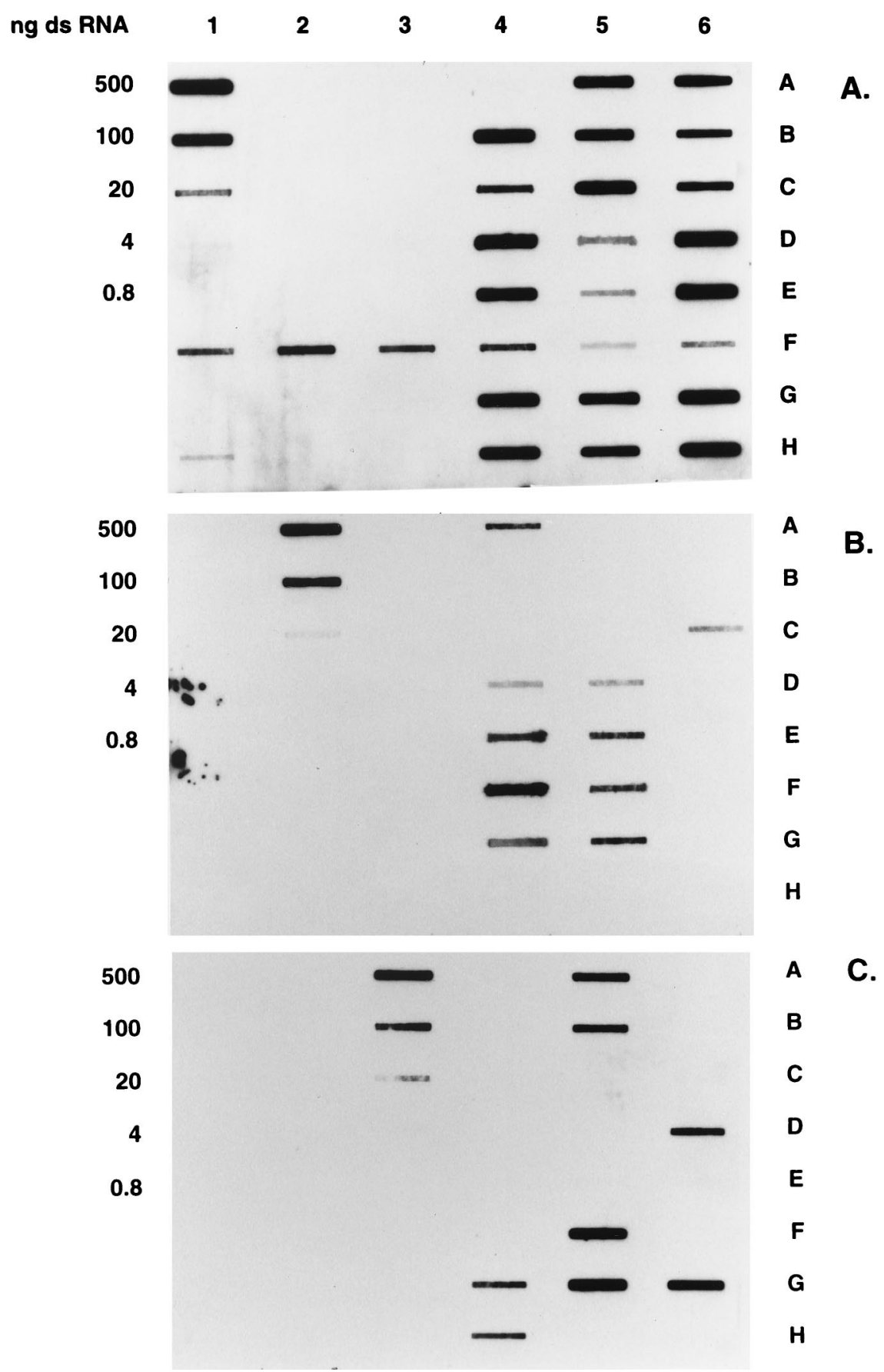

FIG. 1. Sensitivity and specificity of rotavirus $\mathrm{P}[8], \mathrm{P}[4]$, and $\mathrm{P}[6]$ riboprobes and $\mathrm{P}$ genotyping of rotaviruses in fecal specimens. Different amounts of denatured, purified dsRNA from strains Wa (P[8]), DS-1 (P[4]), and M37 (P[6]) were filtered onto nylon membranes (panels A through C; columns 1, 2, and 3; rows A through D), UV-cross-linked, and hybridized with DIG-labeled riboprobes to the hypervariable regions of strains Wa (panel A), DS-1 (panel B), and M37 (panel C) with hybridization temperatures of 56, 68 , and $68^{\circ} \mathrm{C}$ for the Wa, DS-1, and M37 probes, respectively, and developed as described in Materials and Methods.

typed in this study; in Indianapolis, although the number of strains analyzed was low $(n=22)$, the combined detection rate of P[6]G9 and P[8]G9 (45\%) was only slightly less than that of $\mathrm{P}[8] \mathrm{G} 1(50 \%)$. The majority (20 of 25$)$ of G9 strains were found in two cities, while none were found in cities located on the east or west coast of the United States. Genotype P[6] strains were found in five cities and represented $6.9 \%$ of the total number of strains analyzed in this study.
Among the least-common strains during 1996 to 1997 was $\mathrm{P}[8] \mathrm{G} 4(1.4 \%)$ together with two globally rare strains, $\mathrm{P}[8] \mathrm{G} 2$ and P[4]G1 (0.3\% each). Strains that were nontypeable for the $\mathrm{P}$ or $\mathrm{G}$ type or both the $\mathrm{P}$ and $\mathrm{G}$ types represented $5.5 \%$ of the total, and $2.3 \%$ of the strains had mixed $\mathrm{G}$ types.

Characteristics of infants infected with G9 strains versus other serotypes. The ages of the 21 infants infected with G9 strains for whom data were available (mean $=16$ months, 


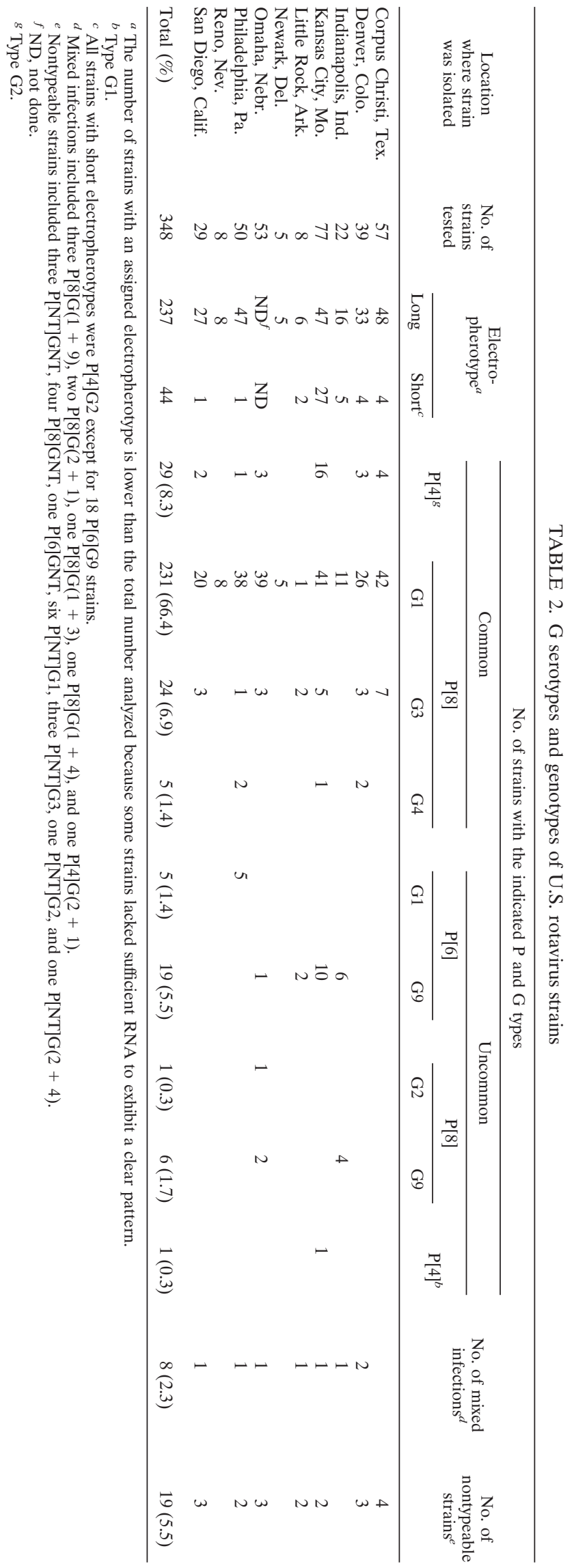

TABLE 3. Reactivity of G9 strains with MAbs

\begin{tabular}{|c|c|c|c|c|c|c|c|}
\hline \multirow{2}{*}{$\begin{array}{l}\text { Strain and } \\
\text { source } \\
\text { (G serotype) }\end{array}$} & \multicolumn{7}{|c|}{$\begin{array}{l}\text { Absorbance (100) with indicated MAb } \\
\text { (G serotype or subgroup specificity) }\end{array}$} \\
\hline & $\begin{array}{l}\text { KU4 } \\
\text { (G1) }\end{array}$ & $\begin{array}{c}\text { S22G10 } \\
(\mathrm{G} 2)\end{array}$ & $\begin{array}{c}\text { YO-1E2 } \\
\text { (G3) }\end{array}$ & $\begin{array}{c}\text { ST-2G7 } \\
\text { (G4) }\end{array}$ & $\begin{array}{l}\text { F45:8 } \\
\text { (G9) }\end{array}$ & $\begin{array}{c}255-60 \\
\text { (SGI) }\end{array}$ & $\begin{array}{r}631-9 \\
\text { (SGII) }\end{array}$ \\
\hline \multicolumn{8}{|l|}{ Culture } \\
\hline KU (1) & 100 & 3 & 3 & 3 & 3 & 37 & 98 \\
\hline DS-1 (2) & 3 & 94 & 3 & 2 & 2 & 101 & 5 \\
\hline P (3) & 2 & 2 & 31 & 2 & 2 & 12 & 34 \\
\hline VA70 (4) & 6 & 5 & 3 & 71 & 15 & 16 & 97 \\
\hline WI61 (9) & 5 & 4 & 5 & 6 & 83 & 33 & 101 \\
\hline $116 \mathrm{E}(9)$ & 3 & 3 & 2 & 5 & 73 & 28 & 72 \\
\hline US- $1071^{a}$ & 2 & 2 & 2 & 2 & 29 & 103 & 95 \\
\hline US- $1205^{a}$ & 3 & 4 & 3 & 4 & 62 & 105 & 7 \\
\hline US- $1206^{a}$ & 4 & 4 & 4 & 4 & 34 & 97 & 9 \\
\hline Mock infection & 2 & 2 & 2 & 2 & 1 & 2 & 1 \\
\hline \multicolumn{8}{|l|}{ Stools } \\
\hline US- $1073^{a}$ & 4 & 5 & 4 & 4 & 22 & 116 & 34 \\
\hline US- $1089^{a}$ & 4 & 4 & 4 & 4 & 27 & 106 & 30 \\
\hline US- $1202^{a}$ & 4 & 4 & 4 & 4 & 14 & 105 & 31 \\
\hline US- $1204^{a}$ & 4 & 4 & 3 & 3 & 92 & 101 & 44 \\
\hline US- $1212^{b}$ & 3 & 2 & 3 & 3 & 15 & 2 & 59 \\
\hline Negative stool & 4 & 4 & 4 & 4 & 3 & 3 & 5 \\
\hline
\end{tabular}

median $=11$ months, range $=0.1$ to 84 months) were very similar to those of 253 children infected with serotypes G1 to G4 for whom data were available (mean $=17$ months, median $=11$ months, range $=0.23$ to 156 months). The percentages of inpatients and outpatients in the two groups were also similar. Among the 21 G9-infected infants, 15 (71\%) were inpatients and $6(29 \%)$ were outpatients, and for 255 children infected with serotypes G1 to G4 for whom data were available, $176(69 \%)$ were inpatients and 79 (31\%) were outpatients. However, additional studies with larger numbers of G9infected infants and more comprehensive patient data will need to be performed so that it can be ascertained if major differences between the groups exist.

Characterization of U.S. G9 strains. A partial characterization of the G9 strains was carried out to confirm our RT-PCR genotyping results. All the P[6]G9 strains had short electropherotypes. Fifteen of these strains that were subsequently culture adapted in MA104 cells had subgroup I VP6 antigens, while four P[8]G9 strains whose RNA profiles were analyzed had long electropherotypes and subgroup II VP6 and antigens (Table 2 and data not shown).

To determine if these strains were antigenically related to serotype G9, selected culture-adapted and fecal G9 strains were tested for binding to specific MAbs (Table 3). Both culture-adapted and fecal G9 strains bound to antibody F45:8, made to prototype G9 strain F45 (P1A[8]G9), but not to MAbs to serotypes G1 to G4. The binding pattern of the U.S. G9 strains was essentially identical to those of prototype serotype G9 strains WI61 and 116E. The U.S. G9 strains did not bind to two other G9-specific MAbs made to prototype strains WI61 (4A5) and F45 (F45:9) (16, 26) (data not shown).

We also sequenced the VP7 open reading frame of P[6]G9 strain US1205 and compared it to those of prototype strains from serotypes G1 to G14 (data not shown). The closest deduced amino acid relationship was to serotype G9 strain WI61 (95.7\% identity), suggesting that US1205 and related strains belong to serotype G9. A relatively high amino acid homology of the G9 strain US1205 with G3 RRV (88.7\%) was also found. 


\section{DISCUSSION}

This surveillance study of current (1996 to 1997) HRV strains in the United States has identified for the first time a high prevalence of novel strains with G9 and P[6] specificity. Strains with these $\mathrm{G}$ and $\mathrm{P}$ types had previously been commonly detected only in developing countries; thus, the appearance of these strains in the United States is unusual and raises questions about whether they represent emerging infections or simply were not diagnosed in the past. Strains that cannot be typed by MAb EIA are always present in rotavirus collections, and most investigators have not attempted to further characterize them; therefore, the possibility exists that these strains have always been present. Since methods such as multiplex RT-PCR and hybridization that permit routine characterization of $\mathrm{P}$ genotypes and the identification of the $\mathrm{G}$ types of nonserotypeable strains have now been developed in several laboratories, including our own, studies of historic collections need to be done to look for G9 and P[6] in the United States. In addition, since the RRV-TV vaccine contains only the VP7 antigens of serotypes G1 to G4, monitoring whether it protects against serotype G9 infection will be important.

Consistent with the findings of numerous published studies, P[8]G1 (66.4\%) was by far the most-common strain overall and in 9 of 10 surveillance centers from which we obtained strains, while P[4]G2 $(8.3 \%)$ was second and P[8]G3 (6.9\%) was third in prevalence. Unexpectedly, P[6]G9 (5.5\%) was the fourthmost-common strain detected, with isolates from four different cities. In addition, P[8]G9 (1.7\%) was detected in two cities, yielding a combined G9 detection rate of $7.2 \%$ (third most prevalent of completely typed strains). The P[6]G9 strains with short electropherotypes and subgroup I specificity have not previously been detected in the United States, but they were recently found to be highly prevalent in Bangladesh (47). Further, strains with the same $\mathrm{P}$ and $\mathrm{G}$ types, but with long electropherotypes and subgroup II antigens, were the second-mostcommon strains found in a survey of rotavirus strains from children with diarrhea in India (38). The other strain, P[8]G9 (subgroup II, long electropherotype), was previously detected only once before in the United States and several times in Japan $(4,19,33,34)$ but has not been reported since. Strains with serotype G9 specificity, subgroup I antigen, and a long electropherotype have also been reported once in Thailand (48).

These results raise to three the number of different countries, including the first industrialized nation, where the rate for detection of type G9 has been found to be elevated in recent rotavirus seasons. This observation raises the possibility that G9 may be a globally important serotype that has been inadequately diagnosed in the past or has emerged as an important serotype in recent years, as suggested by the finding that G9 was not detected before 1995 in a 10-year study in Bangladesh by Unicomb and colleagues (47). In addition, the detection rate of $\mathrm{P}[6]$ strains $(6.9 \%)$ in this study and in surveys from several developing countries, such as India, Bangladesh, and Brazil, has raised similar questions $(38,45,47)$.

The epidemiologic significance of G9 and P[6] rotaviruses will need to be defined through continued surveillance and typing of strains from historic collections analogous to the Bangladeshi study (47). In the short term, such studies will need to be conducted by RT-PCR and hybridization methods, such as those used in the present study, until MAbs that react specifically with G9 strains in fecal specimens are identified. We detected G9 in the present study and in the Bangladeshi study only because several years ago we developed RT-PCR primers specific for an unusual serotype G9 infection of neo- nates in India $(3,7)$ to use in a multiplex RT-PCR system for G types G1 to G4 and G9 strains $(7,18)$. One possible antibody for immunoassay development is F45:8, which was shown in this and another recent study to react with some stool specimens containing G9 strains from the United States and Bangladesh as well as culture-adapted strains from the United States, Bangladesh, and India (Table 3 and reference 47).

Sequence analysis confirmed that the VP7 gene of G9 strain US1205 was highly homologous to serotype G9 strain WI61, both overall ( $\sim 96 \%$ amino acid identity) and in the major antigenic regions of VP7 (A to C), strongly suggesting that this strain and related U.S. G9 strains belong to serotype G9. Consistent with this possibility, these strains and genotype G9 strains from Bangladesh and one serotype G9 strain from India (116E) all reacted with MAb F45:8 (Table 3) (47). The relatively high $(\sim 89 \%)$ amino acid identity between the VP7 protein of US1205 and RRV VP7 raises the possibility of antigenic relationship with this G3 strain. However, the antigenic regions (A to $\mathrm{C}$ ) primarily responsible for $\mathrm{G}$ serotype determination are highly distinct between US1205 and RRV, so whether there is any cross-neutralization between these strains remains to be seen. The study of this issue and, subsequently, the determination of whether vaccination with the RRV-TV vaccine (containing the G3 RRV parent) protects against diarrhea caused by serotype G9 are important.

We also evaluated a riboprobe method for P genotyping of rotavirus strains in fecal specimens. This method was at least as efficient as previous methods with ${ }^{32} \mathrm{P}$-labeled PCR products from the same region of VP4 for P genotyping (28), and the maximum sensitivity of $0.8 \mathrm{ng}$ was also comparable. Hybridization with riboprobes has the same limitation of other methods with long probes in that high concentrations of heterologous RNAs can lead to low-level cross-hybridization. Consequently, appropriate standard strain and fecal RNA controls are essential for reliable $\mathrm{P}$ genotyping by dot or slot blot hybridization methods. Nonetheless, this method shows promise as a lessexpensive, less-labor-intensive alternative to the "gold standard" method, RT-PCR.

\section{ACKNOWLEDGMENTS}

This work was supported in part by a grant from the National Vaccine Program. We thank John O'Connor for editorial assistance and the Biotechnology Core Facility of the CDC for synthesizing all the oligonucleotides used in this study.

M. Ramachandran, C. D. Kirkwood, and S. Jin are supported by a fellowship from the Veterans Administration Medical Center, Atlanta, $\mathrm{Ga}$.

\section{REFERENCES}

1. Ando, T., S. S. Monroe, J. R. Gentsch, Q. Jin, D. C. Lewis, and R. I. Glass. 1995. Detection and differentiation of antigenically distinct small roundstructured viruses (Norwalk-like viruses) by reverse transcription-PCR and Southern hybridization. J. Clin. Microbiol. 33:64-71.

2. Both, G. W. 1985. Unpublished data.

3. Cicirello, H. G., B. K. Das, A. Gupta, M. K. Bhan, J. R. Gentsch, R. Kumar, and R. I. Glass. 1994. High prevalence of rotavirus infection among neonates born at hospitals in Delhi, India: predisposition of newborns for infection with unusual rotavirus. Pediatr. Infect. Dis. J. 13:720-724.

4. Clark, H. F., Y. Hoshino, L. M. Bell, J. Groff, G. Hess, P. Bachman, and P. A. Offit. 1987. Rotavirus isolate W161 representing a presumptive new human serotype. J. Clin. Microbiol. 25:1757-1762.

5. Clark, H. F., P. A. Offit, R. W. Ellis, J. J. Eiden, D. Krah, A. R. Shaw, M. Pichichero, J. J. Treanor, F. E. Borian, L. M. Bell, and S. A. Plotkin. 1996. The development of multivalent bovine rotavirus (strain WC3) reassortant vaccine for infants. J. Infect. Dis. 174(Suppl. 1):S73-S80.

6. Coulson, B., L. E. Unicomb, G. A. Pitson, and R. F. Bishop. 1987. Simple and specific enzyme immunoassay using monoclonal antibodies for serotyping human rotaviruses. J. Clin. Microbiol. 25:509-515.

7. Das, B. K., J. R. Gentsch, H. G. Cicirello, P. A. Woods, A. Gupta, M. Ramachandran, R. Kumar, M. K. Bhan, and R. I. Glass. 1994. Character- 
ization of rotavirus strains from newborns in New Delhi, India. J. Clin. Microbiol. 32:1820-1822.

8. Das, B. K., J. R. Gentsch, Y. Hoshino, S.-I. Ishida, O. Nakagomi, M. K. Bhan, R. Kumar, and R. I. Glass. 1993. Characterization of the G serotype and genogroup of New Delhi newborn rotavirus strain 116E. Virology 197: 99-107.

9. Devereux, J., P. Haeberli, and O. Smithies. 1984. A comprehensive set of sequence analysis programs for the VAX. Nucleic Acids Res. 12:387-395.

10. Estes, M. 1996. Rotaviruses and their replication, p. 1625-1655. In B. N Fields, D. M. Knipe, and P. M. Howley (ed.), Fields virology, 3rd ed., vol. 2. Lippincott-Raven Press, Philadelphia, Pa.

11. Felsenstein, J. 1989. PHYLIP-phylogeny inference package (version 3.2). Cladistics 5:164-166.

12. Flores, J., J. Sears, I. P. Schael, L. White, D. Garcia, C. Lanata, and A. Z Kapikian. 1990. Identification of human rotavirus serotype by hybridization to polymerase chain reaction-generated probes derived from a hyperdivergent region of the gene encoding outer capsid protein VP7. J. Virol. 64:40214024.

13. Gentsch, J. R., R. I. Glass, P. Woods, V. Gouvea, M. Gorziglia, J. Flores, B. K. Das, and M. K. Bhan. 1992. Identification of group A rotavirus gene 4 types by polymerase chain reaction. J. Clin. Microbiol. 30:1365-1373.

14. Gentsch, J. R., P. A. Woods, M. Ramachandran, B. K. Das, J. P. Leite, A. Alfieri, R. Kumar, M. K. Bhan, and R. I. Glass. 1996. Review of G and P typing results from a global collection of strains: implications for vaccine development. J. Infect. Dis. 174(Suppl. 1):S30-S36.

15. Gerna, G., A. Sarasini, S. Arista, A. Di Mateo, L. Giovanelli, M. Parea, and P. Halonen. 1990. Prevalence of human rotavirus serotypes in some European countries 1981-1988. Scand. J. Infect. Dis. 22:5-10.

16. Gerna, G., A. Sarasini, M. Parea, S. Arista, P. Miranda, H. Brussow, Y. Hoshino, and J. Flores. 1992. Isolation and characterization of two distinct human rotavirus strains with G6 specificity. J. Clin. Microbiol. 30:9-16.

17. Gorziglia, M., K. Green, K. Nishikawa, K. Taniguchi, R. Jones, A. Z. Kapikian, and R. M. Chanock. 1988. Sequence of the fourth gene of human rotaviruses recovered from asymptomatic or symptomatic infections. J. Virol. 62:2978-2984

18. Gouvea, V., R. I. Glass, P. Woods, K. Taniguichi, H. F. Clark, B. Forrester, and Z. Y. Fang. 1990. Polymerase chain reaction amplification and typing of rotavirus nucleic acid from stool specimens. J. Clin. Microbiol. 28:276-282.

19. Green, K. Y., Y. Hoshino, and N. Ikegami. 1989. Sequence analysis of the gene encoding the serotype-specific glycoprotein (VP7) of two new human rotavirus serotypes. Virology 168:429-433.

20. Green, K. Y., J. F. Sears, K. Taniguchi, K. Midthun, Y. Hoshino, M. Gorziglia, K. Nishikawa, S. Urasawa, A. Z. Kapikian, R. M. Chanock, and J. Flores. 1988. Prediction of human rotavirus serotype by nucleotide sequence analysis of the VP7 protein gene. J. Virol. 62:1819-1823.

21. Greenberg, H., V. McAuliffe, J. Valdesuso, R. Wyatt, J. Flores, A. Kalica, Y. Hoshino, and N. Singh. 1983. Serological analysis of the subgroup protein of rotavirus using monoclonal antibodies. Infect. Immun. 39:91-99.

22. Hum, C. P., M. L. Dyall-Smith, and I. H. Holmes. 1989. The VP7 gene of a new $G$ serotype of human rotavirus (B37) is similar to $G 3$ proteins in the antigenic $\mathrm{C}$ region. Virology 170:55-61.

23. Kantharidis, P., M. L. Dyall-Smith, and I. H. Holmes. 1987. Marked sequence variation between segment 4 genes of human RV-5 and simian SA-11 rotavirus. Arch. Virol. 93:111-121.

24. Kapikian, A. Z., J. Flores, T. Vesikari, T. Ruuska, H. P. Madore, K. Y. Green, M. Gorziglia, Y. Hoshino, R. M. Chanock, K. Midthun, and I. PerezSchael. 1991. Recent advances in development of a rotavirus vaccine for prevention of severe diarrheal illness of infants and young children, p. 255 264. In J. Mestecky et al. (ed.). Immunology of milk and the neonate. Plenum Press, New York, N.Y

25. Kilgore, P. E., R. C. Holman, M. J. Clarke, and R. I. Glass. 1995. Trends of diarrheal disease-associated mortality in U.S. children, 1968 through 1991. JAMA 274:1143-1148.

26. Kirkwood, C., P. J. Masendycz, and B. S. Coulson. 1993. Characteristics and location of cross-reactive and serotype-specific neutralization sites on VP7 of human $\mathrm{G}$ type 9 rotaviruses. Virology 196:79-88.

27. Laemmli, U. K. 1970. Cleavage of structural proteins during the assembly of the head of bacteriophage T4. Nature 227:680-685.

28. Larralde, G., and J. Flores. 1990. Identification of gene 4 alleles among human rotaviruses by polymerase chain reaction-derived probes. Virology 179:469-473.

29. Leite, J. P., A. A. Alfieri, P. Woods, R. I. Glass, and J. R. Gentsch. 1996. Rotavirus $\mathrm{G}$ and $\mathrm{P}$ types circulating in Brazil: characterization by RT-PCR, probe hybridization, and sequence analysis. Arch. Virol. 141:2365-2374.
30. Mackow, E. R., R. D. Shaw, S. M. Matsui, P. T. Vo, M. N. Dang, and H. B. Greenberg. 1988. The rhesus rotavirus gene encoding protein VP3: location of amino acids involved in homologous and heterologous rotavirus neutralization and identification of a putative fusion region. Proc. Natl. Acad. Sci. USA 85:645-649.

31. Masendycz, P. J., E. A. Palombo, R. J. Gorrell, and R. F. Bishop. 1997. Comparison of enzyme immunoassay, PCR, and type-specific cDNA probe techniques for identification of group A rotavirus gene 4 types. J. Clin. Microbiol. 35:3104-3108.

32. Matson, D. O., M. K. Estes, J. W. Burns, H. B. Greenberg, K. Taniguchi, and S. Urasawa. 1990. Serotype variation of human group A rotaviruses in two regions of the USA. J. Infect. Dis. 162:605-614.

33. Nakagomi, O., T. Nakagomi, K. Akatani, N. Ikegami, and N. Katsushima. 1990. Relative frequency of rotavirus serotypes in Yamagata, Japan, over four consecutive rotavirus seasons. Res. Virol. 141:459-463.

34. Nakagomi, T., K. Akatani, N. Ikegami, N. Katsushima, and O. Nakagomi. 1988. Occurrence of changes in human rotavirus serotypes with concurrent changes in genomic RNA electropherotypes. J. Clin. Microbiol. 26:25862592.

35. Offit, P. A., H. F. Clark, G. Blavat, and H. B. Greenberg. 1986. Reassortant rotaviruses containing structural proteins VP3 and VP7 from different parents induce antibodies protective against each parental serotype. J. Virol. 60: 491-496.

36. Parashar, U. D., R. C. Holman, M. J. Clarke, J. S. Bresee, and R. I. Glass. 1997. Hospitalizations associated with rotavirus diarrhea in the United States, 1993 through 1995: surveillance based on the new ICD-9-CM rotavirus-specific diagnostic code. J. Infect. Dis. 177:13-17.

37. Pereira, H. G., V. S. Gouvea, and A. M. Fialho. 1986. A comparison of simian rotavirus SA11 preparations maintained in different laboratories. Mem. Inst. Oswaldo Cruz 81:389-393.

38. Ramachandran, M., B. K. Das, A. Vij, R. Kumar, S. S. Bhambal, N. Kesari, H. Rawat, L. Bahl, S. Thakur, P. A. Woods, R. I. Glass, M. K. Bhan, and J. R. Gentsch. 1996. Unusual diversity of human rotavirus G and P genotypes in India. J. Clin. Microbiol. 34:436-439.

39. Reddy, D. A., H. B. Greenberg, and A. R. Bellamy. 1989. Nucleotide sequence of St. Thomas 3 rotavirus genomic segment 9: an RNA encoding the major serotypic antigen. Nucleic Acids Res. 17:449.

40. Richardson, M. A., A. Iwamoto, N. Ikegami, A. Nomoto, and Y. Furuichi. 1984. Nucleotide sequence of the gene encoding the serotype-specific antigen of human (Wa) rotavirus: comparison with the homologous gene from simian SA11 and UK bovine rotaviruses. J. Virol. 51:860-862.

41. Sereno, M. M., and M. I. Gorziglia. 1994. The outer capsid protein VP4 of murine rotavirus strain Eb represents a tentative new $\mathrm{P}$ type. Virology 199: 500-504.

42. Smith, E. M., M. K. Estes, D. Y. Graham, and C. P. Gerba. 1979. A plaque assay for the simian rotavirus SA11. J. Gen. Virol. 43:513-519.

43. Taniguchi, K., T. Urasawa, Y. Morita, H. B. Greenberg, and S. Urasawa. 1987. Direct serotyping of human rotavirus in stools using serotype 1-, 2-, 3-, and 4-specific monoclonal antibodies to VP7. J. Infect. Dis. 155:1159-1166.

44. Timenetsky, M. D., V. Gouvea, N. Santos, R. C. Carmona, and Y. Hoshino. 1997. A novel human rotavirus serotype with dual G5-G11 specificity. J. Gen. Virol. 78(Pt. 6):1373-1378.

45. Timenetsky, M. D. S. T., N. Santos, and V. Gouvea. 1994. Survey of rotavirus $\mathrm{G}$ and $\mathrm{P}$ types associated with human gastroenteritis in São Paulo, Brazil, from 1986 to 1992. J. Clin. Microbiol. 32:2622-2624.

46. Torok, T. J., P. E. Kilgore, M. J. Clarke, R. C. Holman, J. S. Bresee, and R. I. Glass. 1997. Visualizing geographic and temporal trends in rotavirus activity in the United States, 1991 to 1996. Pediatr. Infect. Dis. J. 16:941-946.

47. Unicomb, L. E., G. Podder, J. R. Gentsch, K. Z. Hasan, A. S. G. Faruque, M. J. Albert, and R. I. Glass. Submitted for publication.

48. Urasawa, S., A. Hasegawa, T. Urasawa, K. Taniguchi, F. Wakasugi, H. Suzuki, S. Inouye, B. Pongprot, J. Supawadee, S. Suprasert, P. Rangsiyanond, S. Tonusin, and Y. Yamazi. 1992. Antigenic and genetic analyses of human rotaviruses in Chiang Mai, Thailand: evidence for a close relationship between human and animal rotaviruses. J. Infect. Dis. 166:227-234.

49. Urasawa, S., T. Urasawa, K. Taniguchi, F. Wakasugi, N. Kobayashi, S. Chiba, N. Sakurada, M. Morita, O. Morita, M. Tokieda, H. Kawamoto, Y. Minekawa, and M. Obseto. 1989. Survey of human rotavirus serotypes in different locales in Japan by enzyme-linked immunosorbent assay with monoclonal antibodies. J. Infect. Dis. 160:44-51.

50. Woods, P. A., J. Gentsch, V. Gouvea, L. Mata, A. Simhon, M. Santosham, Z.-S. Bai, S. Urasawa, and R. I. Glass. 1992. Distribution of serotypes of human rotavirus in different populations. J. Clin. Microbiol. 30:781-785. 